\title{
Exploring information experiences through phenomenography
}

\author{
Christine Yates, Helen Partridge, Christine Bruce
}

\begin{abstract}
Phenomenography is a qualitative research approach that seeks to explore variation in how people experience various aspects of their world.

Phenomenography has been used in numerous information research studies that have explored various phenomena of interest in the library and information sphere. This paper provides an overview of the phenomenographic method and discusses key assumptions that underlie this approach to research. Aspects including data collection, data analysis and the outcomes of phenomenographic research are also detailed. The paper concludes with an illustration of how phenomenography was used in research to investigate students' experiences of web-based information searching. The results of this research demonstrate how the phenomenographic approach yields insights into variation, making it possible to develop greater understanding of the phenomenon as it was experienced, and to draw upon these experiences to improve and enhance current practice.
\end{abstract}

\section{Introduction}

Information experience is emerging as a new focus in information research. A focus on experience offers a holistic approach to understanding peoples' engagement with information. It takes into account the interrelations between people and their broader environments in a manner which considers people and

\section{Authors}

Christine Yates is a Doctoral Candidate in Information Studies at Queensland University of Technology. Her research is investigating how health information literacy is experienced among Australians aged 45-64 years. Christine has a strong research interest in community information literacy.

Email: cl.yates@qut.edu.au

Helen Partridge is Professor in the Information Studies Group, School of Information Systems at Queensland University of Technology in Australia. Her research focuses on the way people experience information in their everyday life, she specializes in qualitative research.

Christine Bruce is Professor in the Information Studies Group, School of Information Systems at Queensland University of Technology. She has an extensive background in qualitative and interpretive research, including phenomenography, action research, and grounded theory. 
their world as inseparable. It also provides deep insights into the ways in which people relate to their informational life-worlds. Phenomenography, the focus on this paper, represents one research approach which can assist us with developing theoretical insights into people's information experiences. Phenomenography seeks to understand variation in people's experiences of different phenomena or aspects of the world. It has been used in information research since the early 1990s, with the first investigation revolving around doctoral students' experiences of literature reviews (Bruce, 1994). This was followed shortly after by two studies, conducted in Sweden (Limberg, 1998) and Australia (Bruce, 1997) examining the experience of information seeking amongst school students, and the experience of effective information use amongst higher educators, respectively. These two studies were each complemented by articles on the phenomenographic research approach and its potential impact for information research (Bruce, 2000; Limberg, 2000, 2005). Whilst numerous studies using phenomenography in information research have been published in recent years (Edwards, 2006; Kirk, 2002; Lupton, 2008; Parker, 2006; Williams \& Wavell, 2007), there has been no recent summary of phenomenography, its theoretical positions and its applicability to information research and practice. This paper will fill that gap. Firstly, the paper will provide a brief overview of the origins of the research approach before discussing key assumptions and principles. Data collection, analysis and the nature of phenomenographic results will also be explored. Secondly, the paper will provide a brief discussion on how the results of a phenomenographic study can be used to change current practice.

\section{Phenomenography}

Phenomenography emerged as a new approach to research in the 1970s and was primarily developed by educational researchers in Sweden (Marton, Dahlgren, Svensson \& Säljö, 1977; Marton \& Svensson, 1979; Säljö, 1979).

Phenomenography emanated out of research led by Ference Marton to investigate variation in student learning outcomes. As a research approach it has historically been concerned with exploring questions relating to learning and understanding, that is, how people learn and how they see knowledge within a particular context (Marton \& Booth, 1997; Svensson, 1997). Phenomenography's focus on learning and the experience of learning in different contexts has meant that learning related phenomena comprise the most typical experiences investigated using this research approach (Edwards, 2007). Furthermore, phenomenography's historical foundation in the discipline of education has endured and its on-going development as a research approach has primarily occurred in this sphere (Limberg, 2000; Marton \& Booth, 1997; Svensson, 1997).

Phenomenography is most frequently described as a research specialisation that aims to map "the qualitatively different ways in which people experience, conceptualise, perceive, and understand various aspects of, and various phenomena in, the world around them" (Marton, 1986, 31). It is underpinned by the notion that people collectively experience and understand phenomena in a number of qualitatively different but interrelated ways (Bruce, 1997; Marton, 1986). Phenomenography is therefore concerned with describing things as they appear to and are experienced by people (Marton \& Pang, 1999). 
Phenomenography is also considered to be a relational approach to research because the object (the phenomenon under investigation) and the research subjects (the people experiencing the phenomenon) are not viewed or treated separately. Instead phenomenographic research focuses on exploring the relations formed between the research subjects and objects or aspects of the world (Bowden, 2000a; Limberg, 2000). It is these inseparable subject-object relations that phenomenography represents as experiences, which when combined represent the phenomenon as a whole.

\subsection{Assumptions of phenomenography}

The development of the phenomenographic approach represented "a reaction against, and an alternative to, the then dominant tradition of positivistic, behaviouristic and quantitative research" (Svensson, 1997, 171). Svensson (1997) discusses how phenomenography constructed its own set of epistemological and ontological assumptions. Whilst the assumptions developed were inspired from several related traditions, Svensson maintains that phenomenography avoided embracing any in their entirety.

Epistemological assumptions relate to the nature of knowledge, that is, the theory and knowledge of truth. According to Marton and Pang (2008), the epistemological stance of phenomenography is based upon the principle of intentionality. This principle embodies a non-dualist view of human consciousness whereby experience is depicted as "an internal relationship between human beings and the world" (Pang, 2003, 145). Hence according to phenomenography, knowledge is constituted through internal relations between people and world; it is conceptualised as a human-world relationship (Bowden \& Marton, 1998; Marton \& Pang, 2008). Marton and Pang (2008, 535) further explain the intentional nature of human experience by emphasising that an individual "cannot experience without something being experienced". Therefore knowledge in phenomenography is understood in terms of the various meanings associated with the phenomena of interest, and the similarities and differences in those meanings (Svensson, 1997). This variation in experience is said to represent 'collective consciousness' about phenomena (Marton \& Booth, 1997).

Ontological assumptions relate to the nature of being, that is questions regarding the nature of reality and the nature of the human being in the world (Denzin \& Lincoln, 2003). In the traditional positivist paradigm, research approaches are frequently based upon a dualist ontology, where the person and the world are viewed as two distinct entities. In contrast, phenomenography is grounded by a non-dualist ontology, whereby the person and the word are viewed and studied in relation to each other. Marton (2000) explains phenomenography's non-dualistic ontological perspective stating:

There are not two worlds: a real, objective world, on the one hand, and a subjective world of mental representations, on the other. There is only one world, a really existing world, which is experienced and understood in different ways by human beings. It is simultaneously objective and subjective

(Marton, 2000, 105). 
A non-dualistic stance therefore assumes there is an inseparable relationship between people and aspects of their world, and exploring this relationship is the focal point of phenomenographic research. This perspective has led to phenomenography being referred to as a relational approach to research. Indeed according to Svensson (1997), because the research object in phenomenography has the character of knowledge, its ontological assumptions become epistemological in a broad sense.

\subsection{A second order perspective}

A key tenet and distinguishing feature of phenomenography is the adoption of a second-order perspective. Through this perspective the researcher is oriented towards describing people's ways of seeing, understanding and experiencing the world around them. Hence in the second-order perspective, phenomena are investigated through the experience of the participants rather than the experience of the researcher (Marton \& Pang, 1999). This assumption is fundamentally linked to how experience is constituted from a phenomenography perspective as being an internal and inseparable relationship between human beings and the world.

Marton first distinguished the 'first-order' and 'second-order' perspective, stating that the former was concerned with describing various aspects of the world, the latter was concerned with describing "people's experiences of various aspects of the world" $(1981,171)$. In comparing the two perspectives, Marton differentiated the first-order perspective as being "from the outside" and the second-order perspective as being "from the inside" $(1981,177)$. It is this insider perspective that Marton (1981) argued as being a distinguishing feature and strength of phenomenography, providing a significant contrast to traditional first-order scientific research where the world is expressed as is.

Marton and Booth (1997) associated the first and second order perspectives as being oriented towards different objects of research. This idea echoes early writings of Marton $(1981,178)$ who observed that research approached from a first-order perspective was concerned with how something really is while the second-order perspective is concerned with how a phenomena is conceived. Consequently the second-order perspective has influence on ways in which research questions are formulated, posing questions of a 'how' and a 'what' nature instead of 'why'. To illustrate this point a phenomenographic study of webbased information searching might ask 'How do people experience web-based information searching?' (second-order perspective) instead of asking 'Why do people search for information on the web?' (first-order perspective).

Phenomenography focuses on investigating the central characteristics of variation in how participants experience a particular phenomenon, instead of the cognitive processes associated with constructing these characteristics, differences and change (Barnard, McCosker \& Gerber, 1999). This focus is described by Marton $(1986,32)$ as an interest in "content of thinking rather than the process of thought or perception". It is important to note here that 'content of thinking' is another way of expressing the knowledge object of phenomenography, the internal relation between people and their world. The focus on this knowledge object 
means that phenomenographic studies consider and treat all experiences of the phenomena of interest as logical and valid. Hence the second-order perspective enables researchers to describe particular aspects of the world from the participant's point of view, that is, to reveal human experience and awareness as an object of research.

\subsection{Knowledge interests of phenomenography}

The knowledge interest of phenomenographic research is concerned with revealing variation in human experience and awareness, and to provide experiential descriptions of this variation (Marton \& Booth, 1997; Sjöström \& Dahlgren, 2002). Marton and Pang describe the knowledge interests of phenomenography as being concerned with "the anatomy of the experience itself, rather than on the anatomy of the mind underlying the experience" $(2008,543)$.

A number of different terms are used interchangeably to represent the knowledge interest of phenomenography. These terms include conceptions, ways of experiencing, ways of seeing and ways of understanding (Marton \& Booth, 1997). In phenomenography a way of experiencing is considered as an "internal relation between the experiencer and the experienced" (Marton \& Booth, 1997, 113). In other words experiences are relational in nature due to their dependency on human activity and the world or reality external to an individual. Marton (1996) also described a way of experiencing something as being dependent upon a person's awareness or consciousness. He expressed the idea of awareness as a person's total experience of the world at any given point in time. Continuing this idea he also posited that two key features are apparent in human awareness. The first of these features is that a person's awareness is layered, because one cannot be aware of all things simultaneously. The second feature of human awareness Marton identified is that that we are all aware of everything at the same time but not in the same way.

According to Marton and Booth (1997) experiences are comprised of both meaning and structure and represented the 'anatomy of experience' using the illustration provided below:

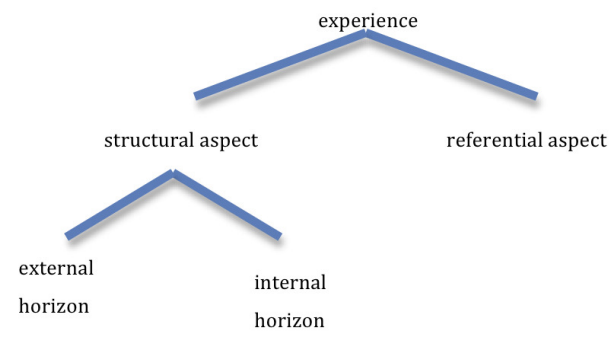

Figure 1: The anatomy of experience (Marton \& Booth, 1997, 88)

Marton and Booth (1997) explain that the referential aspect represents the meaning of an experience and the structural aspects represent its structure. These two aspects of an experience occur simultaneously and are dialectically intertwined (Marton \& Booth, 1997). 
The structural aspect of an experience is the "combination of features discerned and focused on by the subject" (Marton \& Pong, 2005, 336) and is comprised of two elements referred to as the external horizon and the internal horizon. The external horizon refers to what is in the background of the experience, sometimes called the perceptual boundary. The internal horizon refers to what is thematised, or in focus, the internal relationship of the phenomenon's parts to each other and its' cohesive whole (Marton \& Booth, 1997). In addition to the structural aspect of an experience there is also the referential aspect, which refers to the particular meaning or label assigned to the experience.

The anatomy of experiencing a phenomenon can be further illustrated by drawing upon an example from Marton and Booth (1997, 86-87). Imagine that you notice a bird (the phenomenon) sitting in a tree while walking through a park. To see the bird at all you need to distinguish it from the surrounding trees and the broader environment. The surrounding trees and the broader environment form the external horizon of the experience.

It is also possible see the various parts of the bird's body, its pointy beak, its colourful plumage, its tail. You are able to differentiate between the bird and the trees and to know that these separate parts of the bird constitute a whole.

Discerning the bird itself, its different parts, and being able to relate these different parts together is what forms the internal horizon of an experience. Together the external horizon and internal horizon comprise the structural aspect of the experience whereby there is "discernment of the whole from the context on one hand and discernment of the parts and their relationships within the whole on the other" (Marton \& Booth, 1997, 87).

In addition the bird (the phenomenon) also has to be seen or identified as a bird by the person experiencing it. Hence the bird itself needs to be assigned a meaning and our prior experiences of this same phenomenon (the bird) assist us to recognise what it represents. This is the meaning or referential aspect of the experience. These two aspects of the experience, the structural and referential aspects are experienced simultaneously and as previously mentioned are closely related.

Finally, it is also useful to reflect on why or how describing ways of experiencing phenomena may be seen as a valuable matter for research interest. Marton and Booth illustrate the significance of gaining understanding about human experience stating that:

... in order to make sense of how people handle problems, situations, the world, we have to understand the way in which they experience the problems, the situations, the world that they are handling or in relation to which they are acting.

(Marton and Booth, 1997, 111).

Hence phenomenography provides a means through which knowledge about the ways in which people experience phenomena can be revealed. 


\subsection{Data collection in phenomenography}

The face-to-face interview is the primary method for data collection in a phenomenographic study (Ashworth \& Lucas, 2000; Dall'Alba, 1996; Marton, 1986, 1996). Other methods such as drawings, focus groups, written surveys and drawings can also be used (Edwards, 2007).

Bruce $(1994,49)$ describes the phenomenographic interview as a "specialised form of the qualitative research interview". Referring to the work of Kvale (1983), Bruce $(1994,49)$ noted several qualities shared between the phenomenographic and qualitative research interview. These qualities are:

- they are centred on the interviewee's life-world;

- they seek to understand the meaning of phenomenon in the interviewee's life-world;

- they are qualitative, descriptive, specific and pre-suppositionless;

- they are focused on certain themes;

- they are open to ambiguities and change;

- they take place in an interpersonal interaction;

- they may be a positive experience.

However the point of departure with the phenomenographic interview is that its purpose is to explore variation in how the participant experiences or understands the phenomenon of interest. Hence the focus of the interview is on the relation between the participant and the research object of interest, rather than the participant or the research object itself (Bruce, 1997). Therefore while data may be gathered at an individual level, phenomenography focuses on collective awareness and variation in how a phenomenon is experienced. In this way, gathering data at the individual level is the starting point for building a picture of collective awareness concerning how particular phenomena may be experienced.

The process of a phenomenographic interview is semi-structured in nature, and described by Trigwell $(2000,68)$ as "exploring at greater and greater depths of thinking without leading". Continuing this idea further, Ashworth and Lucas (2000, 302) suggest that interviews be considered as a 'conversational partnership' where the interviewer supports a process of reflection. Interview questions are distinctively open-ended in nature and are designed to orient the participant towards the phenomenon of interest. Open-ended questions also allow the participant to select the dimensions of the question they wish to answer (Marton, 1994) and to remain true to the participant's thought processes (Marton $\&$ Booth, 1997). However, despite the use of set questions, Marton (1986) notes that different interviews may proceed down quite different paths. Hence the open structure of questions enables the interviewer to pursue unanticipated lines of reasoning that may lead to new reflections (Booth, 1997).

Åkerlind, Bowden and Green (2005) describe the phenomenographic interview as a process that uses a specific number of set questions and considerable use of unstructured probes to follow up or further investigate the participant's responses. They comment how during the unstructured components of the interview it is imperative that the researcher does not introduce ideas into the interview that the participant has not already expressed. Bowden (2005) also stresses the importance 
of ensuring that the interviewer refrains from making judgemental comments during the interview process, irrespective of whether these are positive or negative in nature.

\subsubsection{Participant selection and sample size}

Purposeful sampling is commonly used in phenomenography, similar to other qualitative research methods. This approach places emphasis on gaining in-depth understanding and provides for the selection of 'information-rich cases' with the potential to produce significant amounts of data of relevance to the research investigation (Patton, 2002, 46). For this reason, the identification of interviewees in phenomenographic studies is typically (and deliberately) non-random as this is influenced by the specific phenomenon that is being explored (Åkerlind, 2005; Booth, 1997; Francis, 1996; Marton, 1986).

Participants in a phenomenographic study should be selected based upon their appropriateness to the purpose of the research study, that is, they have experience of the phenomenon being explored. As noted by Ashworth and Lucas, the 'selection of participants should avoid presupposition about the nature of the phenomenon or the nature of the conceptions held by particular "types" of individuals while observing common-sense precautions about maintaining "variety" of experience' (Ashworth \& Lucas 2000, 300). Fundamentally the aim of participant selection is for a purposive sample likely to uncover variation.

While there is no prescriptive sample size for a phenomenographic study, Bruce maintains this needs to be of sufficient size to gather suitably rich descriptions of people's varying conceptions about the phenomenon of interest (1997). Trigwell (2000) and Bowden (2005) similarly agree, and propose that the sample size for a phenomenographic study is influenced by two factors. In the first instance the number of interviews conducted needs to be sufficient to allow for finding variation in conceptions. Furthermore, sample size must also ensure that the amount of resulting data remains manageable. Other authors propose sample size is determined by a saturation point, with data collection continuing until no additional conceptions of the phenomenon under investigation can be discerned (Dunkin, 2000; Morse, 1994; Sandberg, 2000; Trigwell, 1994).

\subsection{Data analysis in phenomenography}

Svensson (1997) explains that the research orientation of phenomenography as a research process and a research tool is primarily concerned with focussing on and describing conceptions, with each conception representing one way in which the particular phenomenon under investigation is experienced. Hence the aim of data analysis in phenomenographic studies is to uncover variation in how the phenomenon under investigation is experienced (Bruce, 2000; Limberg, 2005).

There is no single process or technique prescribed for the analysis of phenomenographic data and an array of approaches are reported in the literature. Although the absence of a distinct approach has been a point of frequent criticism (Ashworth \& Lucas, 2000; Francis, 1996; Richardson, 1999; Säljö, 1997; Uljens, 1996), other authors contend that given the nature of this type of research, this is 
neither possible or desirable (Bruce, 1997; Johansson, Marton \& Svensson, 1985; Prosser, 2000; Säljö, 1988).

In discussing data analysis, Akerlind (2002) concurs that despite the lack of methodological algorithms, common principles of practice exist: Firstly, by setting aside or limiting any predetermined views or drawing conclusions too quickly about the nature of the categories of description; secondly, ensuring that a focus on the collective experience is maintained by viewing the transcripts and the emerging categories of description as a set (instead of individual transcripts and categories of description); finally, there is a search for meaning or variation in meaning across interview transcripts, and the structural relationships between these meanings.

Bruce $(1997,104)$ describes the analysis process as being "an interplay between the researcher's understanding, the nature of the phenomenon being studied and the style of the available data". In other words in phenomenography, the process of analysis and the outcomes the process produces are constituted through the relationship between the researcher and the data. Walsh (2000) also offers comment on the process, proposing that analysis requires the researcher to more than merely record the different ways participants talk about the phenomenon, but be able to delve behind what is said and how the particular phenomenon is understood. This may be achieved by working across the data as opposed to focussing on what individuals say separately or in isolation from each other.

An early approach to data analysis in phenomenographic studies is provided by Marton, Carlsson and Halasz (1992) who detailed a four stage approach to data analysis. These stages involved: identifying relevant data as 'pools of meaning'; sorting data into 'pools of meaning' based on similarity and exclusive of reference to individual participants; contrasting groups of similar data and writing a category of description for each; and finally verifying a portion of the data by engaging an independent judge to establish inter-judge reliability.

Säljö (1997) similarly concurred with this approach but expanded the process with an additional two stages to precede the four detailed above. The first of these entailed the researcher familiarising themselves with the data in order to develop an understanding of patterns within it. Secondly, the researcher needed to increase their focus on the understanding of conceptions. This involved viewing the data and engaging in self-questioning in terms of how the phenomenon was understood, the concepts used to explain it and its similarities with other phenomena.

Sandberg $(1994,86)$ instead offers a five phase process for phenomenographic analysis. This process comprised becoming familiar with the transcripts; the referential aspect of the analysis; the structural aspect of the analysis; the intentional constitution of the conception and establishing the outcome space of the conceptions.

In contrast, other researchers have reported utilising a process involving an even greater number of stages. Both Dahlgren and Fallsberg (1991) and McCosker, Barnard and Gerber (2004) detailed a seven stage cycle of analysis. The stages comprised familiarisation, condensation, comparison, grouping, articulating, 
labelling and contrasting. They described the technique of analysis as being an iterative rather than sequential process that continues until the analysis is complete.

The intended outcome from the process or technique used for data analysis is the identification of a number of categories that reflect the various ways in which the phenomena is experienced (Edwards, 2007; Walsh, 2000). The categories identified aim to describe the ways in which the phenomenon under investigation is experienced by the collective rather than the individual by focusing on the experience of the phenomenon, not the individuals or people in the study.

\subsection{Phenomenographic results}

The results or outcomes of phenomenographic research are presented as categories of description and an outcome space. The purpose of this is to illustrate and communicate the characteristics of conceptions of the phenomenon of interest (i.e., ways of experiencing the phenomenon) (Bruce, 1997). Each of these terms will now be discussed.

\subsubsection{Categories of description}

It is important to firstly distinguish the difference between the knowledge interests of phenomenography, that is conceptions (i.e., ways of experiencing), and how this relates to the categories of description. These two terms have often been confused in phenomenographic work and are a point of frequent criticism (Trigwell, 1997; Bowden, 2000a). Johansson, Marton and Svensson explain:

Conceptions, which make up our unit of analysis, refer to whole qualities of human-world relations. They also refer to the qualitatively different ways in which some phenomenon or some aspect of reality is understood. When trying to characterise these conceptions, we use some categories of description. The categories are, however, not identical with conceptions - rather they are used to denote them."

(Johansson, Marton and Svensson, 1985, 249).

Bowden (2000a) concurs with this idea, insisting that while categories of description must be as faithful as possible to the individual's ways of experiencing, they cannot be seen as equivalent in nature. Bowden also comments that the formation of categories is based on distinctive features that differentiate one way of experiencing the phenomenon from another (Bowden, 2000b).

Sandberg (1997) suggests that a primary distinction between conceptions and categories of description is the focus on individual or collective ways of experiencing. Thus while conceptions refer to people's ways of experiencing a particular aspect of reality, categories of description represent multiple or collective conceptions. In the same way Marton and Booth (1997) explained this difference stating:

When we talk about 'a way of experiencing something' we usually do so in terms of individual awareness ... When we talk about 'categories of description' we usually do so in terms of qualitatively different ways a phenomenon may appear 
to people of one kind or another. Thus categories of description refer to the collective level

(Marton and Booth, 1997, 128).

Four key qualities underpin the categories of description. Marton $(1988,181)$ describes these qualities as relational (the subject-object relation comprising the conception); experiential (based on the experience of participants in the study); content oriented (focused on the meaning of the phenomenon under investigation); and finally qualitative (descriptive in nature). Pursuing this further, Marton and Booth $(1997,152)$ later proposed three criteria for the quality of a set of categories of description. They suggest:

i. Each category should reveal something distinct about a way of experiencing a phenomenon.

ii. Each category should stand in a logical relationship with other categories.

iii. The number of categories in a set is determined by the extent of variation. In any event it is limited in number.

Categories of description are typically expressed in the form "something (x) is seen as something (y)" (Lybeck, Marton, Stromdahl \& Tullberg, 1988, 101). Bruce (1997) explains that each expression serves as a label for the particular category it represents. As explained earlier, each category of description details the referential and structural aspects of how the phenomenon is experienced. This involves describing the difference in meaning in terms of the primary focus of each experience, and the difference in structure (that is the structure of awareness). In addition, each category of description is accompanied by a prose description of the category along with illustrative quotes sourced from interview data (Bruce, 1997). Quotes from interview transcripts serve to illustrate how each category differs from the other categories identified (Booth, 1997; Bowden, 2000a; Marton, 1994, 1986; Walsh, 2000).

\subsubsection{Outcome space}

The final outcome of phenomenographic research involves representing the categories of description in an outcome space (Barnard, McCosker \& Gerber, 1999; Bruce, 1997; Marton, 1994). The outcome space portrays the complex of different experiences which together comprise the phenomenon, and represents the phenomenon in the same way as categories of description represent conceptions. Marton $(2000,105)$ describes the outcome space as being "the logically structured complex of the different ways of experiencing an object", acting as a "synonym for phenomenon". Therefore in phenomenography, the outcome space represents both the phenomenon as well as the various ways in which it can be experienced.

The outcome space may be illustrated as a table, image or diagram and serves the purpose of depicting how each category relates to each other. Bruce describes the outcome space as a "diagrammatic representation" $(1997,87)$ of the categories of description, while Säljö $(1988,44)$ suggests it reflects a "map of a territory" interpreting how people conceive a particular aspect of reality. 
Laurillard distinguished three different types of outcome space that reflect various ways in which the structural relations between categories may be viewed:

- an inclusive, hierarchical, outcome space in which the categories further up the hierarchy include previous, or lower, categories

- an outcome space in which the different categories are related to the history of interviewee's experience of the phenomenon, rather than to each other

- an outcome space which represents a developmental progression, in the sense that the conceptions represented by some categories have more explanatory power than others $(1993,45)$.

However, irrespective of the type of outcome space to emerge Marton and Booth $(1997,125)$ suggest the need for:

- categories of description to stand in clear relation to the phenomenon;

- categories of description to stand in a logical relationship with one another, a relationship that is frequently hierarchical; and

- the system to be parsimonious, that is, as few categories should be explicated as is feasible and reasonable for capturing the critical variation in the data.

Furthermore, while the outcome space serves as a vehicle for communicating the ways in which people experience a particular phenomenon, it is not feasible to suggest that it captures all possible ways in which this may be experienced or conceived (Marton \& Booth, 1997). Hence the outcome space in phenomenographic research represents how the participants of the study constituted the phenomenon of interest along with the variation therein.

\section{Using phenomenography to improve practice}

This section draws upon the work by Partridge and Edwards (2004) to illustrate how phenomenography can be used to improve practice. A phenomenographic approach was used to explore students' experiences of web-based information searching with a view to improve and enhance university curriculum.

\subsection{Background}

ITB322 Information Resources is an elective subject taken by students enrolled in the Bachelor of Information Technology at the Queensland University of Technology. The subject introduces students to the value of information both personally and professionally and introduces the wide variety of information resources available. There is a major focus on the identification of user needs and the development of information searching skills across a wide variety of online resources, including bibliographic databases and the Internet. The main assessment is a practical assignment in which students are required to use the online searching process to meet a client's specific information need. On-going evaluation of the subject revealed that a number of elements were working well in the subject, for example students talked about their ability to both transfer the knowledge gained to other subjects, and to help their peers when they searched for information. However, the areas of improvement were also noted; whilst students could discuss the many elements of the online searching process, they had trouble 
in combining these elements together and applying them to the successful completion of this assignment. For example, students were able to select appropriate search tools, identify key concepts and synonyms but had difficulty in drawing these together to create search statements appropriate to each specific tool chosen. The challenge for the unit's teaching staff was to identify how the current existing environment could be carefully re-constructed to bring about change (i.e. to make the assignment 'work harder') without detracting from the elements in the environment that were working well.

\subsection{Understanding practice with phenomenography}

Teaching and learning research to date has found that the best way to learn something (be it a skill or a concept) is to experience what you are learning in qualitatively changed ways (Marton \& Booth, 1997). By experiencing a skill or concept in different ways, an individual is able to compare their original (or old) experience of that skill or concept to their new experience of the skill or concept. The individual therefore, is given the opportunity to discern the variation between the old and the new experiences, and according to Runesson (1999) it is this process of discernment that is a significant attribute of learning.

Edwards (2006) has applied this view of learning to information searching. Using the phenomenographic method, Edwards identified variation in the experience of information searching in the online environment. Participants in the study were 32 students from six of the eight academic faculties within the Queensland University of Technology. Different cultures, ages and genders were represented. Four categories that captured the variation in the students' different ways of searching and learning to search for information were identified. The categories include:

Category 1: Information searching is seen as looking for a needle in a haystack Category 2: Information searching is seen as finding a way through a maze Category 3: Information searching is seen as using the tools as a filter Category 4: Information searching is seen as panning for gold.

These four categories can be mapped into an outcome space (Figure 2). The outcome space reflects the hierarchical relationship between the categories. Each of the four categories is associated with different meanings being assigned to the search experience. They are also associated with different awareness structures, different approaches to learning, and different search outcomes (Edwards, 2006). The presence of two columns in the outcome space is significant. On the left hand side, students who experience searching through the first category do not perceive structure within their search environment, although they may know that structure does indeed exist in the searching tools being used, and that this structure could help them in their searching endeavours. In contrast is the column on the right hand side: students who experience searching through the remaining three categories describe using the structure within the search environment to help with the search process. The categories can, therefore, be divided between those that include an experience with structure and those that do not (Edwards, 2006). 


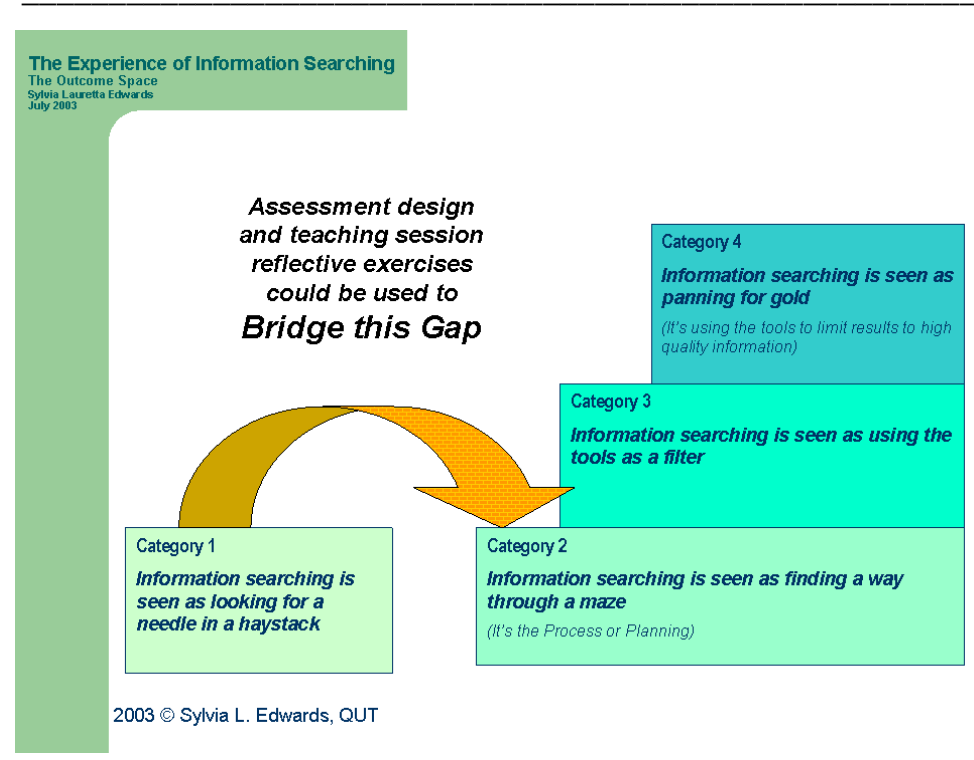

Figure 2: The experience of information searching outcome space (Edwards, 2006)

A detailed summary and discussion on each category and the different meanings assigned to each search experience can be found in Edwards (2006). In short, Edwards concluded that for students to successfully develop information searching skills the teaching and learning environment needs to be designed to encourage "students...to see things happening differently to what they have previously experienced in order to discern a difference" (Edwards, 2004, 112). That is, students need to experience the wide variation of online searching experiences so they may compare and contrast these different experiences to their own. Edwards contends that "if we can do this, we will move our students into a deeper understanding of the searching experience, we will provide them the opportunity to discern a variation in what they have previously experienced, and, hopefully, we may encourage learning" (Edwards, 2004, 112). Edwards provides four guiding principles when designing a learning experience that will allow students to experience variation: provide students with opportunities for reflection; improve assessment to make it both authentic and to encourage students to see the variation; use online tools to further enhance the learning experience; and finally, encourage staff development to enable understanding and application of the findings. The principles outlined by Edwards were used to guide the design and development of the Reflective Online Searching Skills (ROSS) environment.

\subsection{The ROSS environment}

The ROSS environment was used to directly support the main assignment. A link to ROSS is provided from the subjects' Blackboard site (see Figure 3). ROSS was incorporated into the learning environment during Weeks 7 through to 13. Each week during this period students attended a three hour computer laboratory based class. 


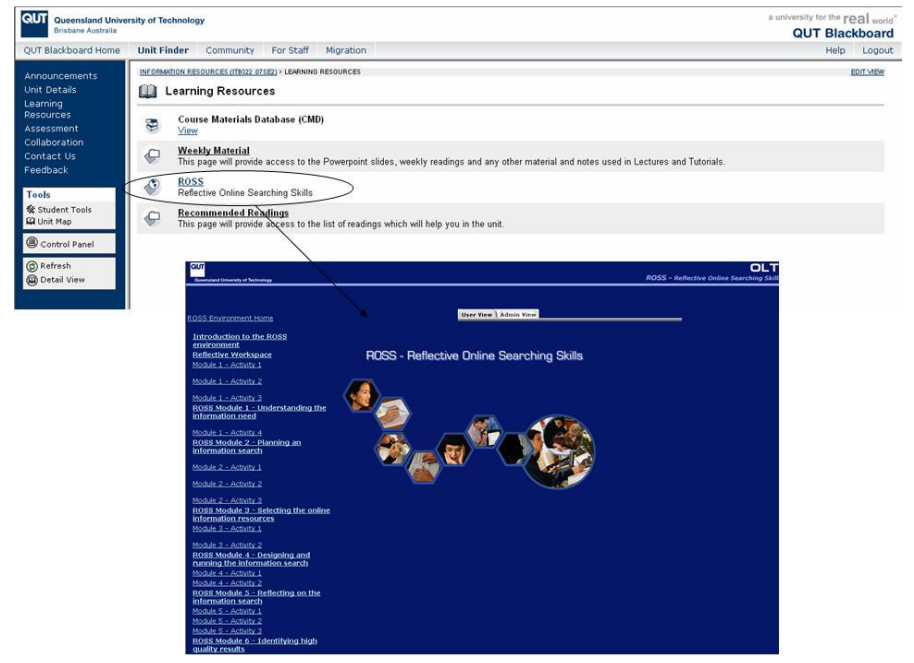

Figure 3: ROSS within the ITB322 Blackboard site

ROSS requires the students to take on the role of an information consultant who has been approached by a client with a specific information need. Figure 4 shows the role play synopsis of the client and the information need.

TO: Jane, Information Broker <info@info.com.au>

FROM: Mr E. Jones (Secretary to Dr Jonas Faultess)<e.jones@promhospital.com.au>

SUBJECT: Request for Information

Dr Jonas Faultless is a world class medical scientist working for a prominent Australian hospital. Dr Faultless has just been informed that due to a colleague's severe illness he will have to give a speech at this year's annual national medical convention. The topic of the presentation is the use of nanotechnology in medicine - this unfortunately is not Dr Faultless' area of expertise. The Doctor would like to obtain information on nanotechnology and its application in medicine. The Doctor is also interested in obtaining some data on who is currently using nanotechnology to aid medical practice. As the presentation is for an Australian conference, Dr Faultless is particularly interested in current use of nanotechnology in the Australian medical context. The Doctor is interested in obtaining the views of experts and researchers in the area and any key organisations. Case studies of the use of nanotechnology in medical practice would be helpful.

\section{Figure 4: The role play scenario}

The student is required to locate information to meet the client's information need by selecting and searching online resources (i.e. Internet search tools or bibliographic databases). The Reflective Online Searching Model guides the student through this process and consequently forms the basis for the ROSS environment. Students are introduced to the overall structure and purpose of the environment in the Introduction to the ROSS Environment page, which is presented in Figure 5. 


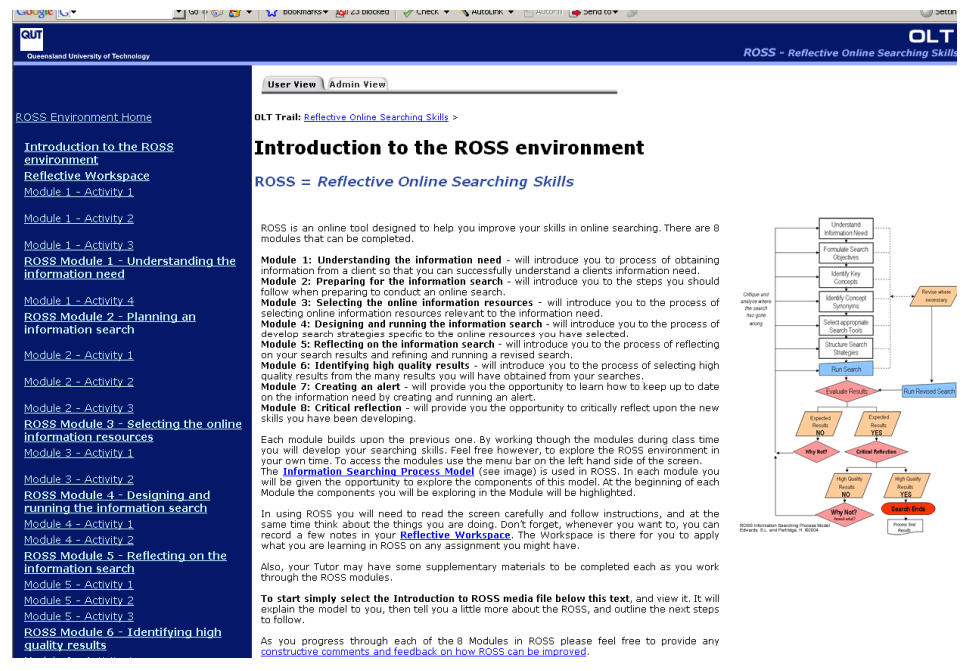

\section{Figure 5: The introduction to ROSS page}

ROSS consists of eight modules. The modules are inter-related, with subsequent modules building upon the former. A brief summary of the eight modules can be found in Figure 6. A short video introduces the students to each module, explaining the purpose of the module and the activities to be completed. Although the students complete the modules in class time, they are also encouraged to use the ROSS environment as a self-paced learning tool that they can access at any time during the course of the unit.

Module 1: Understanding the information need - introduces the process of obtaining
information from a client to successfully understand a clients information need.

Module 2: Preparing for the information search - introduces the steps to follow when preparing to conduct an online search.

Module 3: Selecting the online information resources - introduces the process of selecting online information resources relevant to the information need.

Module 4: Designing and running the information search - introduces the process of develop search strategies specific to the online resources selected.

Module 5: Reflecting on the information search - introduces the process of reflecting on search results and refining and running a revised search.

Module 6: Identifying high quality results - introduces the process of selecting high quality results from the many results obtained from the searches.

Module 7: Creating an alert - introduces how to keep up to date on the information need by creating and running an alert.

Module 8: Critical reflection - provides the opportunity to critically reflect upon the new skills developed.

\section{Figure 6: The 8 ROSS modules}

Each module is interactive, requiring the students to answer questions, make observations and complete exercises. For example, in Module 2 students are introduced to the steps involved in planning and preparing the online search. Students are invited to view a short video introducing the Module and its learning objectives. After watching the video, students are asked to complete Activity 1 by selecting the appropriate link on the menu on the left-hand side of the screen. 
Students are required in Activity 1 to respond to a series of questions which encourage the student to engage with, and reflect upon, the video content. Responses to each of the questions are recorded in the notepads provided. By selecting the Save Button, the students' answers are permanently recorded for them to return to at a later date. After completing Activity 1 students are invited to commence Activity 2 by selecting the appropriate link on the menu on the lefthand side of the screen. Figure 7 shows an excerpt from Module 2 Activity 1.

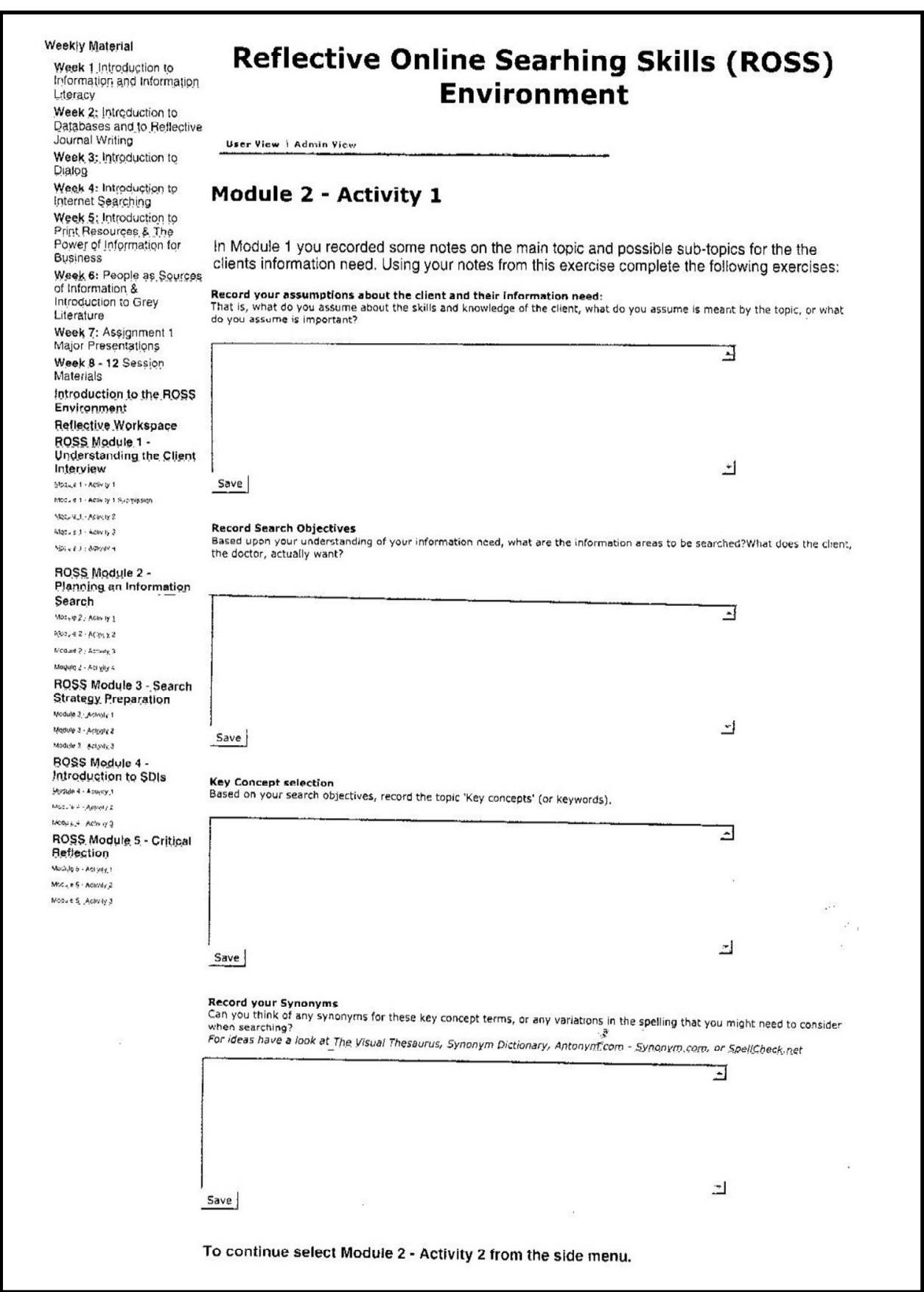

Figure 7: ROSS Module 2 Activity 1 


\subsection{Changing practice with phenomenography}

A number of evaluation strategies were used to obtain data from both stakeholders in the intervention - the teaching staff and the students. Student evaluation was obtained by eliciting comments via the fortnightly Reflective Learning Journal and from self administered questionnaire and semi-structured interviews with students at the end of each semester. The results of the evaluation are available from Partridge and Edwards (2004). In short, both the students and the teaching staff viewed the experience of using ROSS favourably. Student responses clearly indicate that ROSS is an online learning tool of merit, they found the environment "easy to use and understand" and that it "increased flexibility in my studies within this unit", "helped me to understand the unit's content" and "improved the teaching and learning value in the unit". Comments received from the students included:

"I now realise that there is more to searching online than typing the keyword to be searched in google.com and pressing the search button"

"I really like how...ROSS [has] been developed to directly relate to what you are doing in the assignment, this is a very good way of putting into practice what you have learnt in class"

From the teaching perspective, ROSS provided a wonderful means of introducing new energy into the unit. The most significant observation noted by the teaching staff was the impact of ROSS upon student learning. Anecdotally, the overall quality of the main assignment had improved, with many of the students showing a sound understanding of the online searching model and being able to effectively apply the model to the information need outlined in the assignment guidelines. For a fuller discussion on the design and evaluation of ROSS, including the phenomenographic study that informed its creation, please see Edwards (2006) and Partridge and Edwards (2004).

\section{Conclusion}

This paper has demonstrated the nature of the phenomenographic method and its application to practice in one context. As increasing attention turns to understanding the nature of peoples' information experiences, phenomenography presents itself as an important research approach for understanding such experiences. Phenomenography's special attention to variation in experience makes it useful for understanding users' experiences of any phenomenon of interest in the library and information sphere. Such phenomenon may be abstract, such as information use, or concrete physical objects such as library building spaces or digital readers. Understanding variation in peoples' experiences makes it possible to be inclusive in both professional practice and the development of research agenda, as well as making it possible to encourage diversity in peoples' approaches to important phenomena. 


\section{References}

Åkerlind, G. S. (2002). Principles and practice in phenomenographic research. In G. S. Åkerlind \& M. Lupton (Eds.), Proceedings of the Current Issues in Phenomenography Symposium, Canberra, Australia. Canberra: Australian National University.

Åkerlind, G. S. (2005). Variation and commonality in phenomenographic research methods. Higher Education Research \& Development, 24(4): 321-334.

Åkerlind, G. S., Bowden, J., \& Green, P. (2005). Learning to do phenomenography: A reflective discussion. In J. A. Bowden \& P. Green (Eds.), Doing developmental phenomenography Melbourne: RMIT University Press. 74102

Ashworth, P., \& Lucas, U. (2000). Achieving empathy and engagement: a practical approach to the design, conduct and reporting of phenomenographic research. Studies in Higher Education, 25(3): 295-308.

Barnard, A., McCosker, H., \& Gerber, R. (1999). Phenomenography: A qualitative research approach for exploring understanding in health care. Qualitative Health Research, 9(2): 212-226.

Booth, S. (1997). On phenomenography, learning and teaching. Higher Education Research \& Development, 16(2): 135-158.

Bowden, J. A. (2000a). The nature of phenomenographic research. In J. A. Bowden \& E. Walsh (Eds.), Phenomenography Melbourne, Australia: RMIT University. 1-18

Bowden, J. A. (2000b). Experience of phenomenographic research: A personal account. In J. A. Bowden \& E. Walsh (Eds.), Phenomenography. Melbourne, Australia: RMIT University. 47-61

Bowden, J. A. (2005). Reflections on the phenomenographic team research process. In J. A. Bowden \& P. Green (Eds.), Doing developmental phenomenography. Melbourne: RMIT University Press. 11-31

Bowden, J. A., \& Marton, F. (1998). The university of learning. London, UK: Kogan Page Ltd.

Bruce, C. (1994). Reflections on the experience of the phenomenographic interview. In R. Ballantyne \& C. Bruce (Eds.), Phenomenography: Philosophy and Practice Conference. Brisbane, Australia: QUT. 47-55

Bruce, C. (1994). Research students' early experiences of the dissertation literature review. Studies in Higher Education. 19(2): 217-229. 
Bruce, C. (1997). The seven faces of information literacy. Adelaide: Auslib Press.

Bruce, C. (2000). Information literacy research: Dimensions of the emerging collective consciousness. Australian Academic and Research Libraries, 31(2): 91109.

Dahlgren, L. O., \& Fallsberg, M. (1991). Phenomenography as a qualitative approach in social pharmacy research. Journal of Social and Administrative Pharmacy, 8(4): 150-156.

Dall'Alba, G. (1996). Reflections on phenomenography: Toward a methodology? Goteburg, Sweden: ACTA Universitas Gothoburgensis.

Denzin, N. K., \& Lincoln, Y. S. (2003). The landscape of qualitative research : theories and issues (2nd ed.). Thousand Oaks, Califorina: Sage.

Dunkin, R. (2000). Using phenomenography to study organisational change. In J. A. Bowden \& E. Walsh (Eds.), Phenomenography. Melbourne, Australia: RMIT University. 137-152

Edwards, S. (2004). Web-based information searching: understanding student experiences in order to enhance the development of this critical graduate attribute. In P. A. Danaher, C. Macpherson, F. Nouwens and D. Orr (Eds). Lifelong learning: Whose responsibility and what is your contribution: Proceedings of the $3^{\text {rd }}$ International lifelong learning conference, Yeppoon, Queensland, Australia, 13-16 June. Rockhampton: Central Queensland University Press.

Edwards, S. (2006). Panning for gold: Information literacy and the net lenses model. Adelaide: Auslib Press.

Edwards, S. (2007). Phenomenography: 'Follow the yellow brick road'!. In S. Lipu, K. Williamson \& A. Lloyd (Eds.), Exploring methods in information literacy research. Wagga Wagga, New South Wales: Centre for Information Studies. 87-110

Francis, H. (1996). Advancing phenomenography: Questions of method. In G. Dall'Alba \& B. Hasselgren (Eds.), Reflections on phenomenography : toward a methodology? Goteborg, Sweden: Acta Universitatis Gothoburgensis. 35-47

Johansson, B. Marton, F. \& Svensson, L. (1985). An approach to describing learning as change between qualitatively different conceptions. In L. H. T. West $\&$ A. L. Pines (Eds.), Cognitive structure and conceptual change New York: Academic Press. 233-257

Kirk, J. (2002). Theorising information use: Managers and their work. (Doctoral dissertation, University of Technology, Sydney). URL:

http://hdl.handle.net/2100/309 
Kvale, S. (1983). The qualitative research interview - a phenomenolgical and hermeneutical mode of understanding. Journal of Phenomenological Psychology, 14: 171-196.

Laurillard, D. (1993). Rethinking university teaching: a framework for the effective use of educational technology. London: Routledge.

Limberg, L. (1998). Att söka information för att lärä: en studie av sampsel mellan informationssökning och lärande. Borås: Valfrid.

Limberg, L. (2000). Phenomenography: a relational approach to research on information needs, seeking and use. The New Review of Information Behaviour Research, 1: 51-67.

Limberg, L. (2005). Phenomenography. In K. E. Fisher, S. Erdelez \& L. McKechnie (Eds.), Theories of information behavior. Medford, New Jersey: Information Today. 280-283

Lupton, M. (2008). Information literacy and learning. Adelaide: Auslib Press.

Lybeck, L., Marton, F., Stromdahl, H., \& Tullberg, A. (1988). The Phenomenography of the 'Mole Concept' in Chemistry. In P. Ramsden (Ed.), Improving learning : new perspectives. London: Kogan Page. 81-108

Marton, F. (1981). Phenomenography - Describing conceptions of the world around us. Instructional Science, 10(2): 177-200.

Marton, F. (1986). Phenomenography - A research approach to investigating different understandings of reality. Journal of thought, 21(3): 28-49.

Marton, F. (1988). Phenomenography: exploring different conceptions of reality. In D. M. Fetterman (Ed.), Qualitative approaches to evaluation in education : the silent scientific revolution. New York: Praeger. 176-205

Marton, F. (1994). On the structure of awareness. In. J. A. Bowden \& E. Walsh (Eds.), Phenomenographic Research: Variations in Method. Melbourne: Office of the Director EQARD, RMIT. 89-100

Marton, F. (1996). Cognosco ergo sum - Reflections on reflections. In G. Dall'Alba \& B. Hasselgren (Eds.), Reflections on phenomenography : toward a methodology? Goteborg, Sweden: Acta Universitatis Gothoburgensis. 163-187

Marton, F. (2000). The structure of awareness. In J. A. Bowden \& E. Walsh (Eds.), Phenomenography. Melbourne, Australia: RMIT University. 102-116

Marton, F. \& Booth, S. (1997). Learning and awareness. Mahwah, NJ: L. Erlbaum Associates. 
Marton, F., Carlsson, M., \& Halasz, L. (1992). Differences in understanding and the use of reflective learning in reading. British Journal of Educational Psychology, 62(1): 1-16.

Marton, F., Dahlgren, L. O., Svensson, L., \& Säljö, R. (1977). Learning and conception of the world around us. Stockholm: Almquist and Wiksell.

Marton, F., \& Pang, M.F. (1999, August). Two faces of variation. Paper presented at the 8th European Conference for Learning and Instruction, Goteborg University, Sweden. URL:

http:www.ped.gu.se/biorn/phgraph/civil/graphica/fmpmf.pdf [Accessed 24 January, 2011].

Marton, F., \& Pang, M. F. (2008). The idea of phenomenography and the pedagogy of conceptual change. In S. Vosniadou (Ed.), International Handbook on Research of Conceptual Change (pp. 533-559). New York, London: Routledge.

Marton, F., \& Pong, W. Y. (2005). On the unit of description in phenomenography. Higher Education Research \& Development, 24(4): 335-348.

Marton, F., \& Svensson, L. (1979). Conceptions of research in student learning. Higher Education, 8: 471-486.

McCosker, H., Barnard, A., \& Gerber, R. (2004). A phenomenographic study of women's experiences of domestic violence during the childbearing years. Online Journal of Issues in Nursing, 9(1): 11p.

Morse, J. (1994). Designing funded research. In N. Denzin \& Y. Lincoln (Eds.), Handbook of Qualitative Research. Thousand Oaks, California: Sage

Publications. 220-235

Pang, M. F. (2003). Two Faces of Variation: on continuity in the phenomenographic movement. Scandinavian Journal of Educational Research, 47(2): 145-156.

Parker, N. J. (2006). Assignments, information and learning: the postgraduate student experience. (Doctoral dissertation, University of Technology, Sydney). URL: http://hdl.handle.net/2100/1060

Partridge, H., \& Edwards, S. (2004). The rippling pond: ruminations and other musings on the development and use of an online learning environment in the Faculty of Information Technology. In OLT 2004 Online Teaching and Learning Conference: Exploring Integrated Learning Environments, 3rd November 2004. Brisbane, Australia: QUT. 149-158.

Patton, M. Q. (2002). Qualitative research and evaluation methods (3rd ed.). Thousand Oaks, California: Sage. 
Prosser, M. (2000). Using phenomenographic research methodology in the context of research in teaching and learning. In J. A. Bowden \& E. Walsh (Eds.), Phenomenography. Melbourne, Australia: RMIT University. 34-46

Richardson, J. T. E. (1999). The concepts and methods of phenomenographic research. Review of Educational Research, 69(1): 53-82.

Runesson, U. (1999, August, 24-28, 1999). Teaching as constituting a space of variation. Paper presented at the $8^{\text {th }}$ EARLI Conference, Göteborg, Sweden.

Säljö, R. (1979). Learning about learning. Higher Education, 8: 443-451.

Säljö, R. (1997). Talk as Data and Practice - a critical look at phenomenographic inquiry and the appeal to experience. Higher Education Research \& Development, 16(2): 173 - 190.

Säljö, R (1988). Learning in educational settings: methods of enquiry. In P. Ramsden (Ed.), Improving learning : new perspectives (pp. 32-48). London: Kogan

Sandberg, J. (1994). Human competence at work: An interpretivist approach. Goteborg University, Sweden: Bas.

Sandberg, J. (1997). Are phenomenographic results reliable? Higher Education Research \& Development, 16(2): 203-212.

Sandberg, J. (2000). Understanding human competence at work: An interpretative approach. Academy of Management Journal, 43(1): 9-25.

Sjöström, B., \& Dahlgren, L. O. (2002). Applying phenomenography in nursing research. Journal of Advanced Nursing, 40(3): 339-345.

Svensson, L. (1997). Theoretical Foundations of Phenomenography. Higher Education Research \& Development, 16(2): 159-171.

Trigwell, K. (1994). The first stage of a phenomenographic study of phenomenography. In J. A. Bowden \& E. Walsh (Eds.), Phenomenographic Research: Variations in Method. Melbourne: Office of the Director EQARD, RMIT. 56-72

Trigwell, K. (1997). Phenomenography: an approach to research. In J. Higgs (Ed.), Qualitative research: discourse on methodologies. Newbury Park, CA: Sage. 71-94

Trigwell, K. (2000). A phenomenographic interview on phenomenography. In J. A. Bowden \& E. Walsh (Eds.), Phenomenography. Melbourne: RMIT. 62-82

Uljens, M. (1996). On the philosophical foundations of phenomenography. In G. 
Dall'Alba \& B. Hasselgren (Eds.), Reflections on phenomenography : toward a methodology? Goteborg, Sweden: Acta Universitatis Gothoburgensis. 103-128

Walsh, E. (2000). Phenomenographic analysis of interview transcripts. In J. A. B. E. W. (Eds.) (Ed.), Phenomenography. Melbourne, Australia: RMIT University. 19-33

Williams, D., A, \& Wavell, C. (2007). Secondary school teachers' conceptions of student information literacy. Journal of Librarianship and Information Science, 39(4): 199-212.

\section{Open access and copyright}

Library and Information Research is an open access journal. A freely available copy of this paper may be downloaded from the journal's website:

http://www.cilipjournals.org.uk/lir

Copyright and associated moral rights in works published in Library and Information Research are retained by the author(s) but this paper may be used freely, with proper attribution, in educational and other non-commercial settings. 